\title{
Nosocomial Infection and Antibiotic-Resistant Threat in the Middle East
}

\author{
Nabil A Nimer \\ Faculty of Pharmacy, Philadelphia University, Amman, Jordan \\ Correspondence: Nabil A Nimer, Email n_nimer@philadelphia.edu.jo
}

\begin{abstract}
The prevalence of nosocomial infections (NIs) is associated with different bacteria found in hospitals. These infections in their extreme conditions result in morbidity and mortality. This study aims to provide a detailed review of literary studies to identify the prevalence of nosocomial infections and antibiotic-resistance specifically in Middle Eastern countries. A literature review approach is followed in this study. It further identifies different causes and effects associated with nosocomial infections in the given regions. Relevant studies were used to extract important information, specifically related to the Middle Eastern countries. The findings indicated that nosocomial infections following antibiotic resistance are an emerging problem in Middle Eastern countries, leading to significant morbidity and mortality. Most frequently reported NIs in Middle East in our review are bloodstream infections (BSIs) (50\%) and surgical site infections (SSIs) (50\%) followed by urinary tract infections (UTIs). Escherichia coli and Klebsiella species among gram-negative bacteria, Staphylococcus aureus among gram-positive bacterial and fungal pathogens such as Candida species are most reported pathogens involved in nosocomial infections and resistance to penicillins, cephalosporins, carbapenems and fluoroquinolones antibiotics were significantly reported. However, most studies showed minimum resistance of pathogens against drug colistin. To control the growth rate of the given condition, government officials are suggested to ensure that hospitals follow adequate healthcare mechanisms. Also, sufficient education must be provided to the hospital staff about the causes and effects of the given disease.
\end{abstract}

Keywords: antibiotic-resistant threat, Middle East, nosocomial infection

\section{Introduction}

Nosocomial infections (NIs) are associated with different toxins or infectious agents that cause infection among patients admitted to the hospital. These infections are likely to spread through hospital boundaries during the patient's hospital stay. ${ }^{1}$ Eighty percent of the NIs are in the form of nosocomial pneumonia infection (NPNEU), nosocomial bloodstream infection (NBSIs), nosocomial urinary tract infections (UTIs) and nosocomial surgical site infections (SSIs). The rate of incidence of NIs varies from one region to another, along with time variations. According to the information provided by the World Health Organization (WHO), out of every group of 100 patients, seven from the developed countries and ten from the developing regions are suspected of nosocomial infection. ${ }^{2}$

Several causes, including patient-, infection- or procedure-related, in addition to pathogen involvement, are associated with the spread of these infections. For instance, Al-Shami and Al-Haimi ${ }^{3}$ provided essential details regarding the causative factors that prevail in SSIs, which are generally associated with the organ/space or incision. SSIs connected to the incision are divided into deep incision SSI and superficial incision SSI, respectively. Organ or spaced-based SSIs are connected to the anatomical parts of the body other than body wall layers opened during the operation. The common signs include the infectious discharge surrounding the wound area, referring to the cellulite draining through the wound. This type of infection is acquired during the operational process either endogenously or exogenously from the operation site. Similarly, the potential risk factors for spread of NPNEU are related to patient care, infection control and procedure. Patient-related factors include chronic or acute disease severity related to patient, prolonged hospitalization, smoking, coma and comorbidities presence. The infection prevention risk factors include inadequate disinfection of respiratory 
care devices, bedding articles, aerosol spread or improper hand hygiene practices and procedural factors include prolonged used of immunosuppressants, corticosteroids and resistance to antibiotics. ${ }^{4-6}$ Use of central vascular catheters (CVCs) as invasive devices in hemato-oncological patients increases risk of NBSIs, specifically central line associated blood stream infection (CLABSI). ${ }^{7}$ The common opportunistic pathogens such as Escherichia coli (E. coli), Klebsiella pneumoniae (K. pneumoniae), Candida albicans (C. albicans), Enterococcus faecium (E. faecium), Staphylococcus aureus ( $S$. aureus), methicillin-resistant Staphylococcus aureus (MRSA), Clostridium difficile (C. difficile) and Acinetobacter baumannii species are among some of the primarily contributing pathogens in different types of NIs during stay in hospital. ${ }^{8,9}$

The exposure to microbes, parasites, fungi and bacteria plays a critical role in leading to NIs during hospitalization and the development of increasing consequences for patients, their families, and the community at broader levels. The most common consequences associated with NIs include increased hospital stay length, high morbidity rate, and mortality. ${ }^{2}$ These consequences significantly affect the cost of patients' healthcare services and further reduce the reliability of available resources, specifically in developing countries. ${ }^{10}$ Shinde and Mohite ${ }^{11}$ identified nurses as the most common individuals exposed to NI diseases since they are involved in dressing, medication, sterilization, and disinfection process of patients.

The treatment of NIs is a long-term process and thus includes the intake of antibiotics among patients. However, the injudicious antibiotic usage developed challenges due to escalated rate of antibiotic resistance. This antibiotic resistance involve microbes and pathogens exposure to drugs due to inappropriate consumption of antibiotics, their over-usage, poor adherence and inadequate doses poses some major threats to patients' health. ${ }^{12}$ The extent of the problem resulted in the decreased production of new antimicrobial drugs development. According to WHO, a warning was raised about the upcoming post-antibiotic era, ${ }^{13}$ as antibiotic resistance contributes to developing an increased societal, personal, and economic burden of illness by significantly increasing patients' healthcare costs and death rate. This further poses a dire threat to antimicrobial therapy. The problem has raised essential health concerns in both developed and developing countries.

Benassi ${ }^{14}$ proved that antibiotic resistance is generally developed due to pharmacists' illegitimate supply of antibiotics. Pharmacies operated without a knowledgeable pharmacist ultimately increase the risks of healthcare burden over the general population. The fact is generally associated with selling and purchasing antibiotics through misinformation. ${ }^{15}$ This results in the acquisition of antibiotic intake without a proper diagnosis, leading to antibiotic resistance risks.

The continuous increase in the development of multidrug-resistant (MDR) bacteria has now been developed as a global concern, contributing towards increased morbidity and mortality rates, increased healthcare bills, patient visits to hospitals and outpatient clinics. ${ }^{16}$ According to $\mathrm{WHO},{ }^{17}$ the development of MDR has limited the treatment modalities of infectious diseases. Zakai ${ }^{18}$ outlined that a remarkable increase in antibiotic resistance has been witnessed.

Therefore, the present study aims to provide a detailed review of the literature regarding the prevalence of nosocomial infections and antibiotic resistance in the Middle East. A detailed discussion regarding causes, types, effects, and treatment methods provided for NIs and threat to antibiotic resistance is also provided. Important information is extracted from relevant studies related explicitly to the Middle Eastern countries.

\section{Causes of Nosocomial Infections}

Nosocomial infections are generally caused by bacteria, fungi, viruses, and parasites. The most commonly growing strains include: coagulase-negative staphylococci, ${ }^{19}$ methicillin-resistant Staphylococcus aureus (MRSA) ${ }^{20}$ enterococci, ${ }^{21}$ etc., and serve as the antimicrobial-resistant strains. The most common reason behind the prevalence of infections is the antimicrobial-resistant strains. Shalini et $\mathrm{al}^{22}$ outlined that the presence and spread of the infectious material is yet another important cause of these infections, as it consists of endogenous organisms, exogenous, ie, cross or environmental infections. Reyes, Bardossy, and Zervos ${ }^{19}$ highlighted vancomycin-resistant enterococcus (VRE) as the most dangerous infection in the hospital environment. Another multicentre surveillance study ${ }^{23}$ conducted in 14 Middle Eastern countries reported higher incidence of BSIs specifically related to PVC, in comparison to USA and Australia. The study reported 470 PVCs (2.32/1000 PVCs per day) and mortality rate of 29.36\%. Most prevalent microorganisms were gram-positive bacteria 
(55.2\%), including 31\% coagulase-negative S. cocci, 14\% S. aureus, 39\% gram-negative bacteria as causative agents of infection, with predominance of $K$. pneumoniae (8\%), 7\% E. coli, 5\% P. aeruginosa and 3\% Enterobacter spp.

Other common risk factors that commonly contribute to the development of such infections are individual age, chronic diseases such as renal failure, malignant tumor, cancer ${ }^{24}$ along with AIDS, low immune status, leukaemia, etc. In addition, therapeutic procedures, endoscopic examinations, ventilation, intubation, surgical procedures, and catheterizations are other causes of nosocomial infections. However, airborne routes and vehicle-borne routes are identified as the critical sites for these infections. Other areas include lower respiratory tract infections, bloodstream infections, surgical site infections, soft tissue infections, gastroenteritis, urinary tract infections, etc. ${ }^{22}$ Heydarpour et $\mathrm{al}^{22}$ provided a basic stance in this regard. The study indicated that, among 6000 patients who underwent open-heart surgery in Iran, approximately 135 patients were affected by nosocomial infections. SSI (52.6\%) was most frequently reported followed by PNEU (37\%), UTI (9.6\%) and BSI (0.8\%). Major pathogens involved in these reported NIs included E. coli, Klebsiella spp. and S. aureus, respectively. E. coli was further found mainly resistant to imipenem (23.3\%), Klebsiella spp. to gentamicin (38.5) and S. aureus to co-trimoxazole (54.2\%).

Similarly, specific surgical procedures have also been identified to cause and spread these infections, especially SSIs, including ventilator-related pneumonia, bloodstream infections, catheter-related UTIs, etc. In addition, the most common risk areas driving these infections include operation theatres, food handlers, burns units, drinking water, dialysis unit, transfusion service units, etc. However, hospital sites such as orthopaedic wards, general wards, and specifically acute surgical wards are identified as places with an increased chance of infection. ${ }^{12,25}$ A study reported 5.4\% prevalence of SSIs in Jordan. Another study reported SSI association with raised morbidity and mortality in CABG-bypass graft surgery of about $16.8 \%$. The major factors include improper infection control practices, antibiotics misuse, type of surgical procedure and overcrowding in wards. ${ }^{40}$ Pathological knowledge regarding the spread of nosocomial infections may contribute to controlling the spread of these infections.

\section{Types of Nosocomial Infections}

According to the National Healthcare Safety Network with the Centre for Disease Control (CDC), nosocomial infections are generally classified into 13 types depending upon their site of infection, which are specified based on their clinical and biological criteria. Surgical site infections, respiratory tract infections, bloodstream infections, nosocomial fungal infections, urinary tract infections, central nervous system infections, nosocomial pneumonia including the bacterial and viral pneumonia, Mycobacterium tuberculosis, legionnaires' pulmonary aspergillosis, etc. are some types of nosocomial infections that have been encountered. ${ }^{26}$ Other common types of infection are provided below.

\section{Central Line-Associated Blood Stream Infections (CLABSIs)}

These types of infection are generally regarded as the deadliest nosocomial infections, with an increased death rate. During the treatment interventions, catheters are placed in the central lines to supply medicines and other fluids in the patient's body. However, their prolonged usage may cause acute bloodstream infections, leading to compromised health and increased cost of healthcare. ${ }^{27}$ Khan, Baig, and Mehboob ${ }^{28}$ outlined that although there is a decrease in the CLABSIs infections in most US hospitals, its prevalence is still observed explicitly in acute surgical and ICU wards.

\section{Catheter-Associated Urinary Tract Infections (CAUTI)}

CAUTI is often characterized as one of the most commonly identified types of nosocomial infection, with a high prevalence globally. ${ }^{19}$ Urinary tract infections (UTIs) account for almost $12 \%$ of the prevalence of infections reported in different hospitals. The endogenous native microflora of patients cause the development of these infections. Catheters placed in the human body serve as an important site for bacteria to enter the human body. However, in some instances, the imperfect drainage from the catheter leads towards the resisted volume of urine, providing a complete site for the survival and development of bacteria. In extreme cases, CAUTI develops complications such as pyelonephritis, meningitis, cystitis and prostatitis, orchitis, and epididymitis, generally found among male patients. ${ }^{28}$ 


\section{Surgical Site Infections (SSIs)}

Surgical site infections are generally found among $2 \%$ to $5 \%$ of patients who underwent surgery. It is recognized as the second most common type of nosocomial infection ${ }^{29}$ that supports the development of Staphylococcus aureus, ${ }^{30}$ which in extreme cases leads to long-term hospitalization and mortality risks. The endogenous microflora of patients is the pathogen that causes the development of SSIs. The incidences of SSI are identified to be $20 \%$, depending upon the surveillance criteria and procedure.

\section{Ventilator-Assisted Pneumonia (VAP)}

VAP is another type of infection that contributes to nosocomial infections among critically ill patients. ${ }^{31}$ Around $9-27 \%$ of patients commonly assisted to ventilator develop VAP, which occurs after the tracheal intubation in less than $48 \mathrm{hrs}$. Approximately $86 \%$ of nosocomial pneumonia is associated with ventilation. High fever, bronchial sounds, and leukopenia are some common symptoms of VAP. ${ }^{28}$

\section{Prevalence of Nosocomial Infections and Antibiotic-Resistance in the Middle East}

Like every other country, Middle Eastern countries are also highly suspected of the prevalence of nosocomial infections. Nasiri et $\mathrm{al}^{32}$ outlined the value of the antimicrobial-resistance of different pathogens in Tehran, Iran. In this study, 3.3\% of patients reported NIs. Highest reported rate of hospital-acquired infections (HAIs) was found to be acquired from bone marrow transplant units. The most common infections identified were bloodstream infections (BSIs), followed by urinary tract infections, surgical sites infections, and lower respiratory tract infections (LRIs). Most frequently reported microbes included Acinetobacter species (14.2\%) (Table 1). Another multicentre surveillance study conducted by Rosenthal et $\mathrm{al}^{23}$ in fourteen Middle Eastern countries reported prevalence of PVC-related BSIs. The results demonstrated overall 58\% prevalence of gram-negative bacteria with E. coli (16\%) and gram-positive of $12 \%$, respectively. P. aeruginosa was most resistant to fluoroquinolones (26.93\%), Acinetobacter baumannii was most resistant to imipenem (IPM) and meropenem (MEM) (25.93\%) and Klebsiella species was most resistant to ceftriaxone or ceftazidime (75\%).

A retrospective study by Al Samawi et $\mathrm{al}^{33}$ at the Hamad General Hospital of Qatar, reported prevalence and antimicrobial susceptibility of $A$. baumannii infection. From the overall patients, 239 (64.3\%) isolates were classified as infectious, with highest prevalence among males (76.2\%). HAIs were reported more frequently $(96.7 \%)$, with maximum resistance against Cefotaxime 58.3\% and minimum resistance against colistin (1.4\%). Considering most frequent infection type, study in Yemen reported surgical site infections (SSIs) as highest prevalence site, which was suspected to be $8 \%$ in $2002,{ }^{34}$ with a high-level raise of $34 \%$ in $2013 .{ }^{35}$ According to Piso et al, ${ }^{36}$ the Syria, Afghanistan, or Eritrea refugee populations are also highly affected by antibiotic resistance leading to nosocomial infections. The most frequent colonization was of extended-spectrum beta-lactamases (ESBL) (23.7\%) followed by MRSA (15.7\%). The susceptibility for clindamycin and rifampin was $100 \%$ (Table 1).

The prevalence rate of nosocomial infections in different hospitals of Jordan was identified by Abu-Harrah, Faris and Gomaa $^{37}$ among three leading hospitals in Jordan. Findings indicated three significant pathogens that contribute to the development of nosocomial infections. These pathogens are Acinetobacter baumannii, Pseudomonas aeruginosa, and Klebsiella pneumoniae. The ICU was also identified as the major department behind the spread of VAP, CLABSI, CAUTI, community-acquired infections, ward-acquired infections, and SSIs. Another study, by Esfahani et al, ${ }^{38}$ reported highest prevalence of Pseudomonas aeruginosa (13.9\%), Klebsiella (11\%), and Escherichia coli (6.4\%) in Iranian population and most resistance was observed against ampicillin, oxacillin, co-trimoxazole, and nitrofurantoin.

Iyer et $\mathrm{al}^{39}$ provided a comparative analysis of the incidences of MRSA among healthcare workers with nosocomial infections in different units of Jeddah hospitals. The study's findings indicated a prevalence rate of MRCA up to $76 \%$, specifically among healthcare workers. Al-Awaysheh's ${ }^{40}$ study identified the prevalence of SSIs in the tertiary hospital of Jordan. The prevalence rate of surgical site infections was $5.4 \%$. In addition, both gram-negative and gram-positive bacteria were found among the recruited individuals with the given values of $57 \%$ and $43 \%$, respectively. The most common etiologies were Escherichia coli (24.5\%) and Staphylococcus aureus (35\%). In addition, antibiotic resistance for 
Table I Summary of Studies Reported in the Middle East Reporting Types of Nosocomial Infections and Resistance to Antibiotic Patterns

\begin{tabular}{|c|c|c|c|c|c|c|c|}
\hline Author & Year & City /Country & $\begin{array}{l}\text { Sample } \\
\text { Size }\end{array}$ & Type of NI & $\begin{array}{l}\text { Pathogen Resistant to } \\
\text { Antibiotics }\end{array}$ & Resistant and Susceptible Antibiotics & Major Findings \\
\hline $\begin{array}{l}\text { Nasiri } \\
\text { et al }\left.\right|^{32}\end{array}$ & 2019 & Tehran, Iran & 11,164 & $\begin{array}{l}\text { BSI, UTI, } \\
\text { SSI, LRI }\end{array}$ & $\begin{array}{l}\text { 1) Acinetobacter species 2) } \\
\text { P. aeruginosa }\end{array}$ & $\begin{array}{l}\text { 1) co-trimoxazole, gentamicin, ciprofloxacin and ceftriaxone. } \\
\text { 2) ampicillin/ sulbactam (87\%) }\end{array}$ & $\begin{array}{l}\text { Overall NI cases } 369 \text { (3.3\%), (14.2\%) Acinetobacter } \\
\text { species, (13.7\%) Escherichia coli, (9.9\%) Pseudomonas } \\
\text { aeruginosa }\end{array}$ \\
\hline $\begin{array}{l}\text { Al Samawi } \\
\text { et } \mathrm{al}^{33}\end{array}$ & 2016 & Qatar & 372 & $\begin{array}{l}\text { Community- } \\
\text { acquired or } \\
\text { hospital- } \\
\text { acquired }\end{array}$ & Acinetobacter baumannii & $\begin{array}{l}\text { Cefotaxime showed maximum resistance (147,58.3\%), colistin } \\
\text { showed minimum resistance }(2,1.4 \%)\end{array}$ & $\begin{array}{l}\text { Most susceptible site for Nls was respiratory tract } \\
(117,48.9 \%) \text {, Nls frequency was highest in medical ICU } \\
(66,28.6 \%)\end{array}$ \\
\hline Piso et $\mathrm{a}^{36}$ & 2017 & $\begin{array}{l}\text { Syrian, Afghan, } \\
\text { or Eritrean } \\
\text { refugees }\end{array}$ & 261 & & $\begin{array}{l}\text { MRSA, ESBL, } \\
\text { carbapenemase-producing } \\
\text { Enterobacteriaceae }\end{array}$ & $\begin{array}{l}\text { Clindamycin susceptibility (100\%); erythromycin ( } 97.4 \%) \text {; } \\
\text { quinolones }(92.3 \%) \text {; TMP/SMP (82\%); fusidic acid ( } 46.2 \%) \text {; } \\
\text { tetracycline }(25.6 \%) \text {, rifampin (100\%) }\end{array}$ & $\begin{array}{l}\text { MRSA colonization was } 15.7 \% \text {, ESBL colonization was } \\
23.7 \% \text {; no carbapenemase producers detected }\end{array}$ \\
\hline $\begin{array}{l}\text { Esfahani } \\
\text { et } \mathrm{al}^{38}\end{array}$ & 2017 & Isfahan, Iran & 1077 & $\begin{array}{l}\text { Respiratory } \\
\text { system, } \\
\text { urinary } \\
\text { system, and } \\
\text { blood }\end{array}$ & $\begin{array}{l}\text { Pseudomonas aeruginosa, } \\
\text { Klebsiella, Escherichia }\end{array}$ & $\begin{array}{l}\text { Ampicillin, oxacillin, co-trimoxazole, and nitrofurantoin were most } \\
\text { resistant }\end{array}$ & $\begin{array}{l}\text { Highest prevalence was found of Pseudomonas } \\
\text { aeruginosa (13.9\%), Klebsiella (I I\%), and Escherichia coli } \\
(6.4 \%)\end{array}$ \\
\hline lyer et al ${ }^{39}$ & 2014 & $\begin{array}{l}\text { Jeddah, Saudi } \\
\text { Arabia }\end{array}$ & & & $\begin{array}{l}\text { Methicillin resistant } \\
\text { Staphylococcus aureus }\end{array}$ & & $\begin{array}{l}\text { MRSA contains SCCmec as genetic material; } \mathrm{SCCmec} \\
\text { contains mecA gene that is known for its ability to } \\
\text { provide resistance against beta-lactam antibiotics }\end{array}$ \\
\hline $\begin{array}{l}\text { Al- } \\
\text { Awaysheh }{ }^{40}\end{array}$ & 2018 & Jordan & 102 & $\begin{array}{l}\text { Surgical site } \\
\text { infections } \\
\text { (SSIs) }\end{array}$ & $\begin{array}{l}\text { Staphylococcus aureus, } \\
\text { MRSA, Escherichia coli, } \\
\text { Pseudomonas, Citrobacter, } \\
\text { Proteus spp., Klebsiella spp. }\end{array}$ & $\begin{array}{l}\text { Highest resistance for ampicillin, minimum for vancomycin, } \\
\text { teicoplanin and linezolid in gram-positive bacteria For gram- } \\
\text { negative bacteria, resistance was maximum for co-amoxiclav, } \\
\text { ciprofloxacin and ampicillin; it was minimum for meropenem, } \\
\text { gentamicin and piperacillin-tazobactam }\end{array}$ & $\begin{array}{l}\text { Overall Nls prevalence was 5.4\%, Staphylococcus aureus } \\
(35 \%) \text {, Escherichia coli (24.5\%) }\end{array}$ \\
\hline $\begin{array}{l}\text { Rosenthal } \\
\text { et } \mathrm{al}^{23}\end{array}$ & 2020 & Multicenter & 149,609 & PVCR-BSI & $\begin{array}{l}\text { 1) } \\
\text { Pseudomonas aeruginosa } \\
\text { 2) Acinetobacter baumannii } \\
\text { 3) Klebsiella pneumoniae }\end{array}$ & $\begin{array}{l}\text { 1) Fluoroquinolones resistance ( } 26.93 \%) \text {, amikacin }(25.00 \%) \text {, } \\
\text { imipenem (IPM) or meropenem (MEM) }(25.93 \%) \text { 2) IPM or MEM } \\
\text { (63.15\%) 3) Ceftriaxone or ceftazidime ( } 75.00 \%) \text {, IPM or MEM or } \\
\text { ertapenem ( } 40.35 \%)\end{array}$ & $\begin{array}{l}\text { Overall gram-negative bacteria prevalence was } 58 \% \text {; } \\
\text { Escherichia coli (16\%), Klebsiella spp. ( I I\%), Pseudomonas } \\
\text { aeruginosa (6\%), Enterobacter spp. (4\%), and others } \\
\text { (Serratia marcescens) (20\%). For gram-positive bacteria, } \\
\text { Staphylococcus aureus was } 12 \%\end{array}$ \\
\hline $\begin{array}{l}\text { Al Rahmani } \\
\text { et } \mathrm{al}^{43}\end{array}$ & 2019 & Oman & 15,733 & $\begin{array}{l}\text { BSI, surgical, } \\
\text { urine, SCF }\end{array}$ & $\begin{array}{l}\text { Gram positive bacteria's, } \\
\text { Gram negative bacteria, } \\
\text { Candida species }\end{array}$ & $\begin{array}{l}\text { No resistance to Colistin and tigecycline Resistance to } \\
\text { meropenem and ciprofloxacin }\end{array}$ & $\begin{array}{l}\text { 67.76\% gram-positive species including (27.3\%) MSSA, } \\
(25.36 \%) \\
\text { S. agalactiae, (16.1\%) MRSA and (12.1\%) CoNS. } 2.63 \% \\
\text { Candida species Gram-negative bacteria included (32.39\%) } \\
\text { E. coli, (22.16\%) P. aeruginosa, (19.97\%) K. pneumoniae and } \\
(5.22 \%) \text { A. baumannii }\end{array}$ \\
\hline $\begin{array}{l}\text { Nouri } \\
\text { et al }{ }^{44}\end{array}$ & 2020 & Iran & 1194 & $\begin{array}{l}\text { CSF, urine, } \\
\text { tracheal } \\
\text { aspiration }\end{array}$ & I) $K$. pneumoniae & 1) Cefotetan (58.2\%) 2) Ceftazidime (73.1\%) & $\begin{array}{l}\text { E. coli }(59.6 \%) \text { was most frequent in UTI specimens, } \\
\text { K. pneumoniae }(3,18.7 \%) \text { from CSF and } K \text {. pneumoniae } \\
(164,27.8 \%) \text { from tracheal aspiration }\end{array}$ \\
\hline
\end{tabular}

Abbreviations: MSSA, Methicillin-sensitive Staphylococcus aureus; CoNS, Staphylococcus, coagulase negative; MRSA, Methicillin-resistant Staphylococcus aureus; ESBL, Extended Spectrum Beta-Lactamase producers; IPM, Imipenem; MEM, Meropenem; CSF, Cerebrospinal fluid; BSI, Bloodstream infection; PVCR-BSI, Peripheral venous catheter-related bloodstream infection; LRI, Lower respiratory infection; UTI, Urinary tract infection; SSIs, Surgical site infections. 
gram-positive bacteria was highest for ampicillin, whereas minimum resistance was observed for teicoplanin, linezolid, and vancomycin. Gram-negative isolates resistance was common for ampicillin, amoxicillin-clavulanate, and ciprofloxacin, and minimum resistance was indicated for piperacillin-tazobactam, gentamicin, and meropenem.

Elgonda $^{41}$ reported another important fungal pathogen, Candida auris, leading to BSIs, UTIs, SSIs and skin abscesses, as its biofilm due to invasion of innate immunity (neutrophils) raises antibiotic resistance among ICU patients. The annual fatality rate in India in 2009 due to C. auris nosocomial outbreak was 20-60\%. The drug resistance mechanism involved increased efflux pump activity of CDRI and MDRI transporters in C. auris. Another cohort study in India among 227 ICU patients reported that antifungal prior exposure in 74 candidiasis reported cases was significantly associated with $C$. auris $(\mathrm{P}<0.001) .{ }^{42}$ Another study was conducted by $\mathrm{Al}$ Rahmani et al ${ }^{43}$ to assess the prevalence rate of resistant pathogens and their susceptibility in Oman. A total of 15,733 retrospective samples were collected, among which gram-negative bacteria was common among $67.76 \%$ samples, whereas gram-positive bacteria was familiar with a ratio of $29 \%$. Overall, $2.63 \%$ of samples were affected by Candida species. In addition, the most common gram-negative isolated bacteria were Escherichia coli, Pseudomonas aeruginosa, and Klebsiella pneumoniae, with the prevalence rates of $32.39 \%, 22.16 \%$, and $19.97 \%$, respectively. However, no resistance was identified for tigecycline and colistin. Isolated resistance was provided for $K$. pneumoniae and E. coli and was initiated through BSI. Gram-positive bacteria that were universally susceptible to linezolid and daptomycin included MSSA with the prevalence rate of $27.23 \%$, MRSA (16.10\%), and Streptococcus agalactiae (25.36\%). From the findings, it was thus concluded that antibiotic prescriptions must be optimized through stewardship interventions.

In patients with secondary infection in Iran, a study ${ }^{44}$ evaluated antimicrobial resistance and presence of microbes in the CSF, UTI and tracheal aspiration indicated that E. coli (59.6\%) was most frequent in UTI specimens, K. pneumoniae $(3,18.7 \%)$ from CSF and K. pneumoniae (164, 27.8\%) from tracheal aspiration.

\section{Effects of and Preventive Measures for Nosocomial Infections and Antibiotic Resistance}

The prevalence of healthcare infections associated with different hospitals is globally common, leading to adverse health effects. These infections are recognized to negatively impact the quality of healthcare, leading to the development of different problems. According to Iyer et al, ${ }^{39}$ nosocomial infections account for $5-10 \%$ of healthcare cases admitted in emergency care. Among various risk factors, Staphylococcus aureus is the most common cause of the development of these healthcare infections. These infections serve to develop an adverse effect on health, leading to severe illness or even death. The rate of these infections is increasing day by day, specifically in the ICU. Staphylococcus aureus further affects the skin and nose of healthy individuals with a prevalence rate of 25-30\%. However, in most complicated cases, these infections lead to the development of different severe diseases. Such bacteria further cause resistance to other antimicrobial drugs.

Halwani et $\mathrm{al}^{45}$ identified that isolated drug resistance bacteria generally cause hazardous issues for individual health since these antimicrobial drugs are highly effective in counter-fighting the effects caused by the diseases leading to the decrease in death rate and illness. The study further outlined that antibacterial-resistant isolates serve as the fundamental cause of disease outbreak and thus give rise to health-related infections, including pneumonia, urinary tract infection, bacteremia, meningitis, and wound infection, and are further associated with the therapeutic infections among different patients. In addition, resistance against the significant antimicrobial drugs began between 1 year to $>10$ years ago. New compounds such as fluoroquinolones and cephalosporins are further suspected of the increased multidrug-resistant bacteria. In addition, nosocomial bacteria like $E$. coli further contribute to developing meningitis, urinary tract infections, extra-intestinal infections, and peritonitis intestinal infections, following resistance to the antimicrobial agents.

Al-Gethamy et al, ${ }^{46}$ in their study, identified that in healthcare centers of Turkey, $16.6 \%$ of the nosocomial infections were developed due to A. baumannii. However, the prevalence rate of these infections was standard among the ICU patients, leading to the development of respiratory tract infections, which were common among $52.5 \%$ of patients. Other bacteria such as Acinetobacter contribute to the development of severe pneumonia and the development of urinary tract infections, bloodstream infections, and infections in other body parts. 
Management of nosocomial infections such as A. baumannii is often difficult due to the increased resistance to antibiotics and the new mechanism of resistance to the treatment. The spread and the development of these infections can be controlled by the effective management of risk factors such as low patient immunity, size, hospital type, prolonged medical measures along with the careful practice of invasive techniques that serve as the most basic routes of infection along with the transmission of antibiotic-resistant bacteria specifically in the hospital boundaries. To control the spread of these infections, it is essential to manage the quality control of the infection controlling practices (ICPs) to develop immunity against these diseases. ${ }^{2}$

Moreover, hospital management needs to develop a surveillance program against the spread of and to control hospital-acquired infections to reduce the spread of diseases. In addition, the national healthcare authority of the Middle Eastern countries must formulate an agency that may oversee the adoption of healthcare policies and preventive measures in different hospitals of these countries. The development of the national expert committee is further essential to provide high-level support to the hospitals in reducing and preventing the spread of nosocomial infections among patients. Infection control and total quality management program are further effective following the supervision of the antimicrobial committee of drug prescriptions to ensure the effective use of carefully prescribed drugs. This can only be implemented by developing institutional leadership, which ensures the provision of funds for ICPs, which includes the provision of supplies, training, dissemination of information, and other related facilities that provide the application of practices that ensure the prevention of nosocomial infections. Finally, health workers need to make hospitals a safe place for patients and the overall community.

\section{Conclusion}

Nosocomial infections following antibiotic resistance are an emerging problem in Middle Eastern countries, leading to significant morbidity and mortality. Most frequently reported NIs in Middle East in our review are BSIs (50\%) and SSIs (50\%) followed by UTIs. Escherichia coli and Klebsiella species among gram-negative bacteria, Staphylococcus aureus among gram-positive bacteria and fungal pathogens such as Candida species are most reported pathogens involved in nosocomial infections, and resistance to penicillin, cephalosporin, carbapenem and fluoroquinolone antibiotics were significantly reported. However, most studies showed minimum resistance of pathogens against the drug colistin. Hence, further studies are required in Middle East to further examine and improve sensitivity of colistin in NIs.

Considering the information presented in this study, government officials need to ensure further studies reporting nationwide surveillance data of antimicrobial resistance and, accordingly, develop adequate healthcare mechanisms followed by regular supervision. In addition, healthcare education programs must add training courses of antibiotic stewardship program to provide the required knowledge of nosocomial infections and their preventive measures.

The present study is significant as no such study focusing on the prevalence of nosocomial infections and antibiotic resistance in Middle Eastern countries has been conducted before. Information provided in this study is valuable and thus serves as an essential contribution to the existing studies of healthcare. Future researchers are suggested to identify measures undertaken by the healthcare sectors to prevent the prevalence of nosocomial infections and antibiotic resistance in Middle Eastern countries.

\section{Data Sharing Statement}

The data will be available for review from the corresponding author on request.

\section{Acknowledgment}

The author highly acknowledges the contribution of all the associated personnel who contributed to the completion of this study.

\section{Funding}

This research did not receive any specific grant from funding agencies in the public, commercial, or not-for-profit sectors. 


\section{Disclosure}

The author declares no conflicts of interest in this work.

\section{References}

1. Siegel JD, Rhinehart E, Jackson M, Chiarello L. 2007 guideline for isolation precautions: preventing transmission of infectious agents in health care settings. Am J Infect Control. 2007;35:S65-S164. doi:10.1016/j.ajic.2007.10.007

2. World Health Organization (WHO). Healthcare-associated infections FACT SHEET. Available from: https://www.who.int/gpsc/country_work/ gpsc_ccisc_fact_sheet_en.pdf. Accessed February 9, 2022.

3. Al-Shami HZ, Al-Haimi MA. Nosocomial infections in six major hospitals in Sana'a capital city and in some governorates in Yemen. Apple Microbiol Open Access. 2018;4:2.

4. Zaragoza R, Vidal-Cortés P, Aguilar G, et al. Update of the treatment of nosocomial pneumonia in the ICU. Critical Care. 2020;24(1):1-3. doi:10.1186/s13054-020-03091-2

5. Di Pasquale M, Aliberti S, Mantero M, Bianchini S, Blasi F. Non-intensive care unit acquired pneumonia: a new clinical entity? Int J Mol Sci. 2016;17(3):287. doi:10.3390/ijms17030287

6. Micek ST, Chew B, Hampton N, Kollef MH. A case-control study assessing the impact of nonventilated hospital-acquired pneumonia on patient outcomes. Chest. 2016;150(5):1008-1014. doi:10.1016/j.chest.2016.04.009

7. Baier C, Linke L, Eder M, et al. Incidence, risk factors and healthcare costs of central line-associated nosocomial bloodstream infections in hematologic and oncologic patients. PLoS One. 2020;15(1):e0227772. doi:10.1371/journal.pone.0227772

8. Peacock SJ, Parkhill J, Brown NM. Changing the paradigm for hospital outbreak detection by leading with genomic surveillance of nosocomial pathogens. Microbiology. 2018;164(10):1213-1219. doi:10.1099/mic.0.000700

9. Tian L, Sun Z, Zhang Z. Antimicrobial resistance of pathogens causing nosocomial bloodstream infection in Hubei Province, China, from 2014 to 2016: a multicenter retrospective study. BMC Public Health. 2018;18(1):1-8. doi:10.1186/s12889-018-6013-5

10. Samuel SO, Kayode OO, Musa OI, et al. Nosocomial infections and the challenges of control in developing countries. African J Clin Exp Microbiol. 2010;11. doi:10.4314/ajcem.v11i2.53916

11. Shinde MB, Mohite VR. A study to assess knowledge, attitude and practices of five moments of hand hygiene among nursing staff and students at a tertiary care hospital at Karad. Int J Sci Res. 2014;3:311-321.

12. Ma YX, Wang CY, Li YY, et al. Considerations and caveats in combating ESKAPE pathogens against nosocomial infections. Adv Sci. 2020;7 (1):1901872. doi:10.1002/advs.201901872

13. Medecins Sans Frontiers. Antibiotic resistance in the Middle East: lessons learned in the prevention and treatment of multidrug-resistant infections. Conference in Amman, Jordan; 2014. Available from: https:/www.reactgroup.org/uploads/news/2014-MSF-Conference-on-ABR-in-the-MiddleEast.pdf. Accessed February 9, 2022.

14. Benassi A. A qualitative analysis of pharmacists' attitudes and practices regarding the sale of antibiotics without prescription in Syria. $J$ Taibah Univ Medical Sci. 2015;10:227-233.

15. Mansour O, Al-Kayali R. Community pharmacists' role in controlling bacterial antibiotic resistance in Aleppo, Syria. Iran J Pharm Res. 2017;16:1612.

16. Ricciardi W, Giubbini G, Laurenti P. Surveillance and control of antibiotic resistance in the Mediterranean region. Mediterr J Hematol Infect Dis. 2016;8:e2016036. doi:10.4084/mjhid.2016.036

17. World Health Organization (WHO). Antimicrobial resistance: global report on surveillance; 2014. Available from: https://www.who.int/drugresis tance/documents/surveillancereport/en/. Accessed February 9, 2022.

18. Zakai SA. Antibiotic resistance in Saudi Arabia and some Middle Eastern countries: current status. Afr J Microbiol Res. 2019;13:151-157. doi:10.5897/AJMR2019.9048

19. Reyes K, Bardossy AC, Zervos M. Vancomycin-resistant enterococci: epidemiology, infection prevention, and control. Infect Dis Clin. 2016;30:953-965. doi:10.1016/j.idc.2016.07.009

20. Tufariello JM, Lowy FD, Kaplan SL. Infection Due to Coagulase-Negative Staphylococci: Epidemiology, Microbiology, and Pathogenesis. Waltham, MA: UpToDate; 2020.

21. Iyer A, Kumosani T, Azhar E, Barbour E, Harakeh S. High incidence rate of methicillin-resistant Staphylococcus aureus (MRSA) among healthcare workers in Saudi Arabia. J Infect Dev Ctries. 2014;8:372-378. doi:10.3855/jidc.3589

22. Shalini S, Vidyasree MD, Abiselvi A, Gopalakrishnan S. Impact and effect of nosocomial infections: a review. Res J Pharm Biol Chem Sci. 2015;6:947-951.

23. Rosenthal VD, Belkebir S, Zand F, et al. Six-year multicenter study on short-term peripheral venous catheters-related bloodstream infection rates in 246 intensive units of 83 hospitals in 52 cities of 14 countries of Middle East: Bahrain, Egypt, Iran, Jordan, Kingdom of Saudi Arabia, Kuwait, Lebanon, Morocco, Pakistan, Palestine, Sudan, Tunisia, Turkey, and United Arab Emirates-International Nosocomial Infection Control Consortium (INICC) findings. J Infect Public Health. 2020;13(8):1134-1141. doi:10.1016/j.jiph.2020.03.012

24. Divatia JV, Pulinilkunnathil JG, Myatra SN. Nosocomial infections and ventilator-associated pneumonia in cancer patients. Oncol Crit Care. 2020;1419-1439. doi:10.1007/978-3-319-74588-6_125

25. Edwardson S, Cairns C. Nosocomial infections in the ICU. Anaesthes Intensive Care Med. 2019;20(1):14-18. doi:10.1016/j.mpaic.2018.11.004

26. Nikulin-Kulinski K. Physical Therapy Clinical Handbook for PTAs. Jones \& Bartlett Learning; 2017.

27. Haddadin Y, Annamaraju P, Regunath H. Central Line-Associated Bloodstream Infections (CLABSI). StatPearls; 2020.

28. Khan HA, Baig FK, Mehboob R. Nosocomial infections: epidemiology, prevention, control and surveillance. Asian Pac J Trop Biomed. 2017;7:478-482. doi:10.1016/j.apjtb.2017.01.019

29. Sattar F, Sattar Z, Mohsin Zaman SA, Akbar S. Frequency of postoperative surgical site infections in a Tertiary care hospital in Abbottabad, Pakistan. Cureus. 2019;11. doi:10.7759/cureus.4243

30. Miller F. Ventilator-associated pneumonia. World Federation of Societies of Anesthesiologists. 2018:1-6. Available from: https://www.wfsahq.org/ components/com_virtual_library/media/5e63c8f14e8a46c186bb0f73eafa2950-atow-382-00-01.pdf. Accessed February 9, 2022. 
31. Kumar A, Ghauri MI, Razzaque S, Jamali A, Mohammad JS. Ventilator associated pneumonia; prevalence and microbial patterns. PCM. 2015;20. Available from: https://www.pjcm.net/index.php/pjcm/article/view/42/40. Accessed February 15, 2022.

32. Nasiri MJ, Goudarzi AM, Aslani HR, Goudarzi M, Zamani S, AdinehKharrat S. Nosocomial infections caused by drug-resistant bacteria in a Referral University Hospital, Tehran, Iran. NBM. 2019;7:64-70.

33. Al Samawi MS, Khan FY, Eldeeb Y, et al. Acinetobacter infections among adult patients in Qatar: a 2-year hospital-based study. Can J Infect Dis Med Microbiol. 2016;2016:1-5. doi:10.1155/2016/6873689

34. Raja'a YA, Salam AR, Salih YA, et al. Rate and risk factors of surgical site infections with antibiotic prophylaxis. Saudi Med J. 2002;23:672-674.

35. Nasser AM, Zhang X, Yang L, Sawafta FJ, Salah B. Assessment of surgical site infections from signs \& symptoms of the wound and associated factors in public hospitals of Hodeidah City, Yemen. Int J Appl. 2013;3:101. doi:10.18332/tid/109227

36. Piso RJ, Käch R, Pop R, et al. A cross-sectional study of colonization rates with methicillin-resistant Staphylococcus aureus (MRSA) and extendedspectrum beta-lactamase (ESBL) and carbapenemase-producing Enterobacteriaceae in four Swiss refugee centres. PLoS One. $2017 ; 12: \mathrm{e} 0170251$. doi:10.1371/journal.pone.0170251

37. Abu-Harirah HA, Faris NS, Gomaa AM. Point prevalence of nosocomial infection in the three main public hospitals in Jordan. Rev Res. 2016;6:15 .

38. Esfahani BN, Basiri R, Mirhosseini SM, Moghim S, Dolatkhah S. Nosocomial infections in intensive care unit: pattern of antibiotic-resistance in Iranian community. Adv Biomed Res. 2017;6:54.

39. Iyer AP, Baghallab I, Albaik M, Kumosani T. Nosocomial Infections in Saudi Arabia Caused by Methicillin Resistance Staphylococcus Aureus (MRSA). Clinical Microbiology: Open Access. OMICS International; 2014.

40. Al-Awaysheh MM. Surgical site infections in a tertiary referral hospital in Amman: causative bacteria and antibiotic susceptibility. Jordan $J$ Biol Sci Short Commun. 2018;11(2):231-233.

41. Elgonda A. Candida auris: an emerging antibiotic-resistant threat. Public Health Rev. 2021;4(1). Available from: https://pubs.lib.umn.edu/index. php/phr/article/view/3912/2879. Accessed February 15, 2022.

42. Rudramurthy SM, Chakrabarti A, Paul RA, et al. Candida auris candidaemia in Indian ICUs: analysis of risk factors. $J$ Antimicrob Chemother. 2017;72(6):1794-1801. doi:10.1093/jac/dkx034

43. Al Rahmany D, Albeloushi A, Alreesi I, et al. Exploring bacterial resistance in Northern Oman, a foundation for implementing evidence-based antimicrobial stewardship program. Int J Infect Dis. 2019;83:77-82. doi:10.1016/j.ijid.2019.04.004

44. Nouri F, Karami P, Zarei O, et al. Prevalence of common nosocomial infections and evaluation of antibiotic resistance patterns in patients with secondary infections in Hamadan, Iran. Infect Drug Resist. 2020;13:2365. doi:10.2147/IDR.S259252

45. Halwani MA, Baha A, Arabia S, et al. Incidence of antibiotic resistance bacteria in Jeddah's Ministry of Health Hospitals, Saudi Arabia. Adv Microbiol. 2015;5:780. doi:10.4236/aim.2015.512082

46. Al-Gethamy MM, Faidah HS, Adetunji HA, et al. Risk factors associated with multi-drug-resistant Acinetobacter baumannii nosocomial infections at a tertiary care hospital in Makkah, Saudi Arabia-a matched case-control study. J Int Med Res. 2017;45:1181-1189. doi:10.1177/ 0300060517706284

Infection and Drug Resistance

Dovepress

\section{Publish your work in this journal}

Infection and Drug Resistance is an international, peer-reviewed open-access journal that focuses on the optimal treatment of infection (bacterial, fungal and viral) and the development and institution of preventive strategies to minimize the development and spread of resistance. The journal is specifically concerned with the epidemiology of antibiotic resistance and the mechanisms of resistance development and diffusion in both hospitals and the community. The manuscript management system is completely online and includes a very quick and fair peer-review system, which is all easy to use. Visit http://www.dovepress.com/testimonials.php to read real quotes from published authors.

Submit your manuscript here: https://www.dovepress.com/infection-and-drug-resistance-journal 